\title{
Seasonal variation in the prevalence of Toxocara eggs on children's playgrounds in the city of Hanover, Germany
}

\author{
Annika Kleine, Andrea Springer and Christina Strube
}

\begin{abstract}
Background: Roundworms of the genus Toxocara are worldwide distributed zoonotic parasites of carnivores. Based on case numbers and the potential impact on human health, the Centers for Disease Control and Prevention (CDC) categorised toxocarosis as one of the most important neglected parasitic diseases. As contact with contaminated soil, e.g. in sandpits, is considered the primary transmission route, data on playground contamination are needed to assess infection risk for children. Here, playground contamination rates and their seasonal variation in the city of Hanover, Germany, were investigated.

Methods: Sand samples were collected monthly over a 12-month period on 46 playgrounds in the city of Hanover, Germany. In total, 1,362 samples were examined for Toxocara eggs and analysed statistically for seasonal influences on potential infection risk.

Results: Contamination rates ranged from 6.5\% (3/46) Toxocara positive sandpits in September to 41.3\% (19/46) in February, while contamination with infective embryonated eggs varied between 2.2\% (1/46) and 23.9\% (11/46).

Compared to September, the month with the lowest contamination rate, significantly more sandpits were positive for Toxocara eggs from January to August and in October, while the prevalence of infective Toxocara eggs was significantly increased only in January and February. Regarding egg numbers, significantly higher total counts were observed in October and from December to June, while infective egg counts were significantly increased only in January, February and April.

Conclusions: Compared to data from 1985, contamination rates have dropped from $55.8 \%$ to an average of $23.2 \%$ in 2011. Even though the observed egg numbers indicate a moderate to low general infection risk, the potential risk to single individuals should not be underestimated, as highly contaminated spots may occur infrequently and independent of season.
\end{abstract}

Keywords: Toxocara, Roundworms, Zoonosis, Geohelminths, Soil-transmitted helminths, Playgrounds, Sandpits, Soil, Children

\section{Background}

Toxocara canis and T. cati are worldwide distributed zoonotic roundworms of domestic and wild canids and felids, respectively, which may cause several forms of disease in paratenic hosts, including humans. Based on the number of people infected, the potential severity of the illness and the possibility of prevention and treatment, the American Centers for Disease Control and Prevention

\footnotetext{
* Correspondence: christina.strube@tiho-hannover.de

Institute for Parasitology, Centre for Infection Medicine, University of Veterinary Medicine Hannover, Buenteweg 17, 30559 Hanover, Germany
}

(CDC) categorises human toxocarosis as one of the five neglected parasitic diseases with priority for public health action [1]. As a consequence of oral infection, several clinical manifestations caused by migrating larvae may arise in humans, which are classified as visceral and ocular larva migrans syndrome (VLM and OLM), covert toxocarosis and neurotoxocarosis [2]. VLM is a multi-systemic disease due to invading Toxocara larvae, causing fever and abdominal as well as respiratory symptoms. OLM may result in retinal granuloma with visual impairment or even loss of eyesight. Covert toxocarosis describes a non- 
specific clinical syndrome with varying symptoms, such as fever, headache, abdominal pain and behavioural disorders. Finally, neurotoxocarosis may cause a number of neurological dysfunctions. Recently, a link between Toxocara exposure and decreased cognitive performance in children has been proposed [3], which is supported by mouse models showing decreased learning ability in infected mice [4].

When excreted by carnivores as definitive hosts, Toxocara eggs are not immediately infective, but embryonate in the environment by developing the infective third-stage larva within the eggshell within three to six weeks under appropriate conditions [5]. Due to their sticky and thick shell, eggs adhere to environmental surfaces and may remain viable for several months under optimal conditions. Humans become infected by ingesting embryonated eggs after contact with contaminated soil or by consumption of contaminated raw vegetables and herbs. Furthermore, the infection may be acquired by ingesting infective thirdstage larvae in raw or undercooked tissues of paratenic hosts (e.g. chicken). Although the relative epidemiological importance of each of these transmission pathways remains unclear, environmental contamination is regarded as the most important source of infection [6].

Human seroprevalence to Toxocara in continental Europe varies between $2.4 \%$ in Denmark and $44 \%$ in Austria with higher values in rural areas [7, 8]. In tropical countries, seroprevalence can be as high as 90\% [9]. However, current data on seroprevalence are lacking for many countries. Due to lower hygienic awareness, frequent hand-to-mouth contact and oral exploration, including geophagy, children are especially at risk of acquiring infections. Children between five and 14 years of age were more frequently found to be Toxocara seropositive than other age classes [10], and a positive correlation between the frequency of playing at public squares and Toxocara seropositivity has been demonstrated [11]. Thus, the occurrence of Toxocara eggs in sandpits needs to be assessed to estimate the infection risk for children when playing on public playgrounds, and inform public health authorities with regard to the implementation of control measures. The last study investigating geohelminth prevalence on public places in Hanover was conducted in 1985 [12] and reported a contamination rate with Toxocara spp. of $55.8 \%$. However, the prevalence of Toxocara spp. in Germany has declined from $6.9 \%$ in dogs and $9.5 \%$ in cats in the years 1984-1991 [13] to $2.8-6.1 \%$ in dogs and $3.9-4.7 \%$ during the years 2003-2012 ([14]; unpublished own diagnostic data based on 2,731 dog and 903 cat samples). Therefore, a re-evaluation of playground contamination rates with Toxocara spp. in the city of Hanover, Germany, seemed necessary and is provided in the presented study.

\section{Methods}

\section{Study area}

Hanover is the capital city of the federal state of Lower Saxony, Germany. It houses about 540,000 inhabitants with $14.8 \%$ below the age of 18 (state of data: November $\left.9^{\text {th }}, 2016,[15]\right)$. The total area of Hanover covers 20,414 ha, $13.2 \%$ of which account for public parks (state of data: January $1^{\text {st }}, 2016$, [15]), including 406 playgrounds. Sand of public sandpits is replaced regularly every three years with sand from gravel pits, whereas sand from other playground features, such as climbing frames is replaced every five years.

\section{Sample collection}

From January to December 2011, sand samples were collected monthly from sandpits of 46 playgrounds. Playgrounds were chosen to represent all districts of Hanover and were distributed approximately evenly over the entire area of the city. Additionally, sand under thirteen climbing frames was sampled monthly from March to December.

Samples were taken in a meandering pattern from the surface layer of sand (maximum depth $2-3 \mathrm{~cm}$ ) where Toxocara eggs are mostly found [16]. A total of five samples per sandpit (about $1 \mathrm{~kg}$ in total) were taken each month, which was later combined into one monthly sample per sandpit (see section below). In addition, sandpits and playgrounds were surveyed for carnivore faeces which were collected and examined by the McMaster method [17].

\section{Preparation of sand samples}

To ensure comparable sample weights, samples were dried at $37{ }^{\circ} \mathrm{C}$. The drying time depended on the original degree of moisture, which was determined by drying a sample subset at $105{ }^{\circ} \mathrm{C}$ according to the Darr method [18]. After drying, the five samples taken from each sandpit per month were mixed in a side sealed bag (Pelle Vakuumverpackung, Spelle, Germany) to obtain one homogenous sample per month.

Of each sample, two fractions of $250 \mathrm{~g}$ each were treated by the egg recovery method as described by Kleine et al. [19]. Briefly, sample fractions were mixed with $250 \mathrm{ml}$ of saturated sodium chloride $(\mathrm{NaCl})$ solution containing $0.2 \%$ Tween $80^{\circ}$ (Carl Roth $\mathrm{GmbH}$, Karlsruhe, Germany). After incubation for $10 \mathrm{~min}$ in a moving water bath and $20 \mathrm{~min}$ on a distributing jigger, samples were transferred to a 11 beaker. Saturated $\mathrm{NaCl}$ solution was added to a total volume of $750 \mathrm{ml}$, and potentially incorporated eggs were allowed to float to the surface for one h. The supernatant was drained through a $25 \mu \mathrm{m}$ sieve; the content of the sieve was transferred by tap water to a 
$50 \mathrm{ml}$ tube and centrifuged at $3000 \times g$ for $10 \mathrm{~min}$. The sediment was microscopically examined for helminth eggs.

\section{Statistical analysis}

Statistical analyses were conducted in R v. 3.3.1 [20]. Generalised linear mixed models (GLMMs) with binomial error structure and logit link function were used to test the effect of sampling month on the likelihood of sandpit contamination with Toxocara eggs. Models were implemented using the $\mathrm{R}$ package lme4 [21]. To account for repeated sampling, playground identity was included as a random factor. Monthly variation regarding the egg numbers per sandpit sample was assessed in GLMMs with negative binomial error structure and log link function because of zeroinflated, overdispersed data, using lme4's "glmer.nb"function. Negative binomial GLMMs also included playground ID as a random factor. Full models were compared to null models containing only the random factor in a likelihood ratio test (R-function "ANOVA", method = "chisq"). Additional models were run including results from sampling of climbing frames.

\section{Results}

Faecal examination

In total, 31 carnivore faecal samples were found over the year on 15 of the 46 playgrounds, 26 of which were attributed to dogs and five to cats. Only one dog sample contained eggs of Toxocara spp. and Trichuris vulpis.

Playground contamination with zoonotic helminth eggs Overall, the percentage of sandpit samples positive for Toxocara eggs was $23.2 \%$, with monthly contamination rates varying between $6.5 \%(3 / 46)$ in September and 41.3\% (19/46) in February. Embryonated infective Toxocara eggs were found in $7.8 \%$ of sandpit samples, ranging from $2.2 \%(1 / 46)$ in July, September, October and November to $23.9 \%(11 / 46)$ in February. Detailed data on monthly contamination rates of sandpits and climbing frames are shown in Fig. 1.
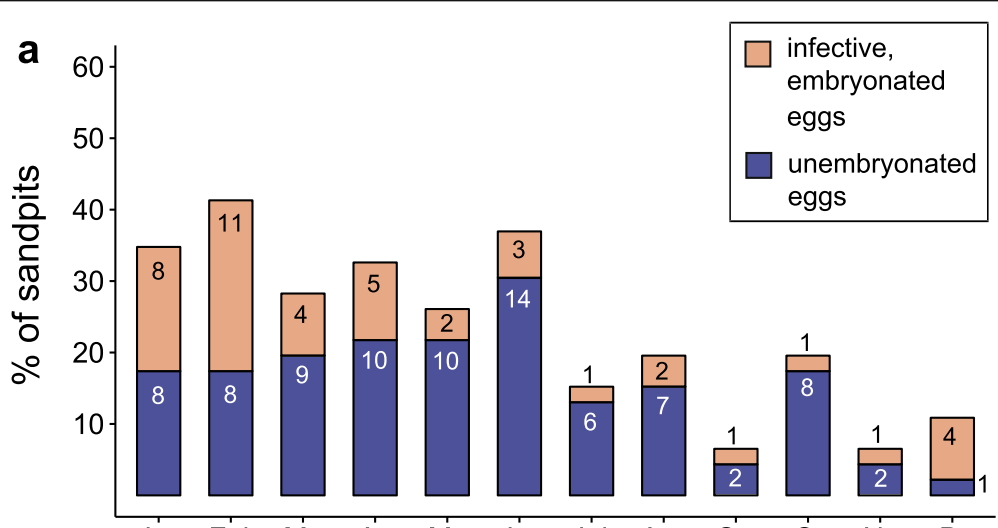

Jan Feb Mar Apr May Jun Jul Aug Sep Óct Nov Dec

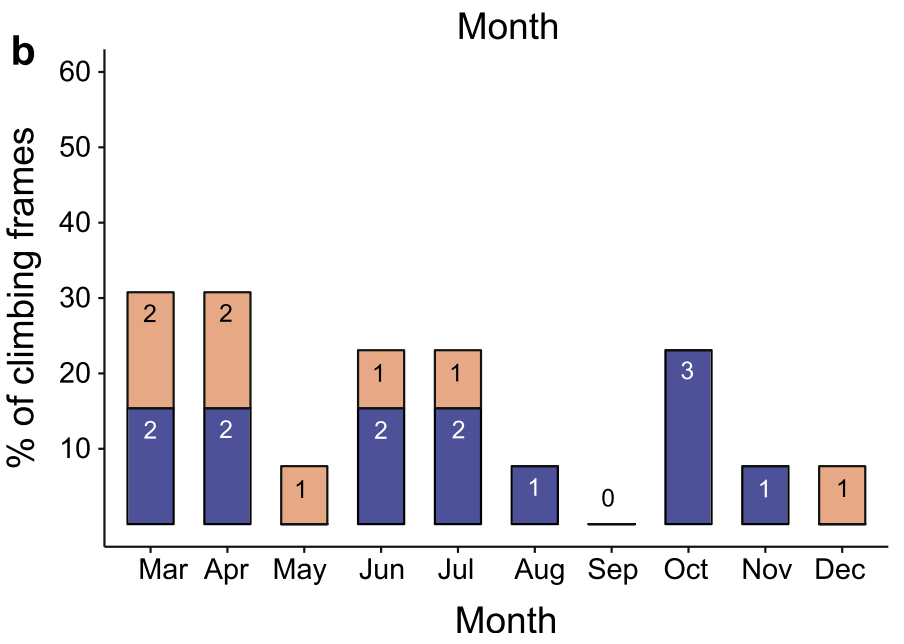

Fig. 1 Monthly contamination rates of $(\mathbf{a})$ sandpits $(n=46)$ and $(\mathbf{b})$ climbing frames $(n=13)$ with Toxocara eggs on the sampled 46 playgrounds in the city of Hanover, Germany. The bars indicate the number of sandpits; the Y-axis indicates the percentage ratio 
The average number of Toxocara eggs per playground varied from 0 to 5.9 eggs in $500 \mathrm{~g}$ of sand over the 1year study period. In positive samples, 1 to 59 eggs (mean: 4.9, SD: 8.6) were observed. Regarding infective eggs, average numbers on positive playgrounds ranged between 0 and 3.58 eggs per $500 \mathrm{~g}$ of sand, with a minimum of 1 egg and a maximum of 36 eggs (mean 1.4, SD: 4.9). Data on total and infective egg numbers on playgrounds are displayed in Fig. 2. Neither hookworm or whipworm eggs nor Ascaris spp. eggs were detected in any sand sample.

\section{Seasonal Toxocara egg contamination}

Overall, the likelihood of sandpit contamination with Toxocara eggs was significantly higher from January to June when compared to September, the month with the

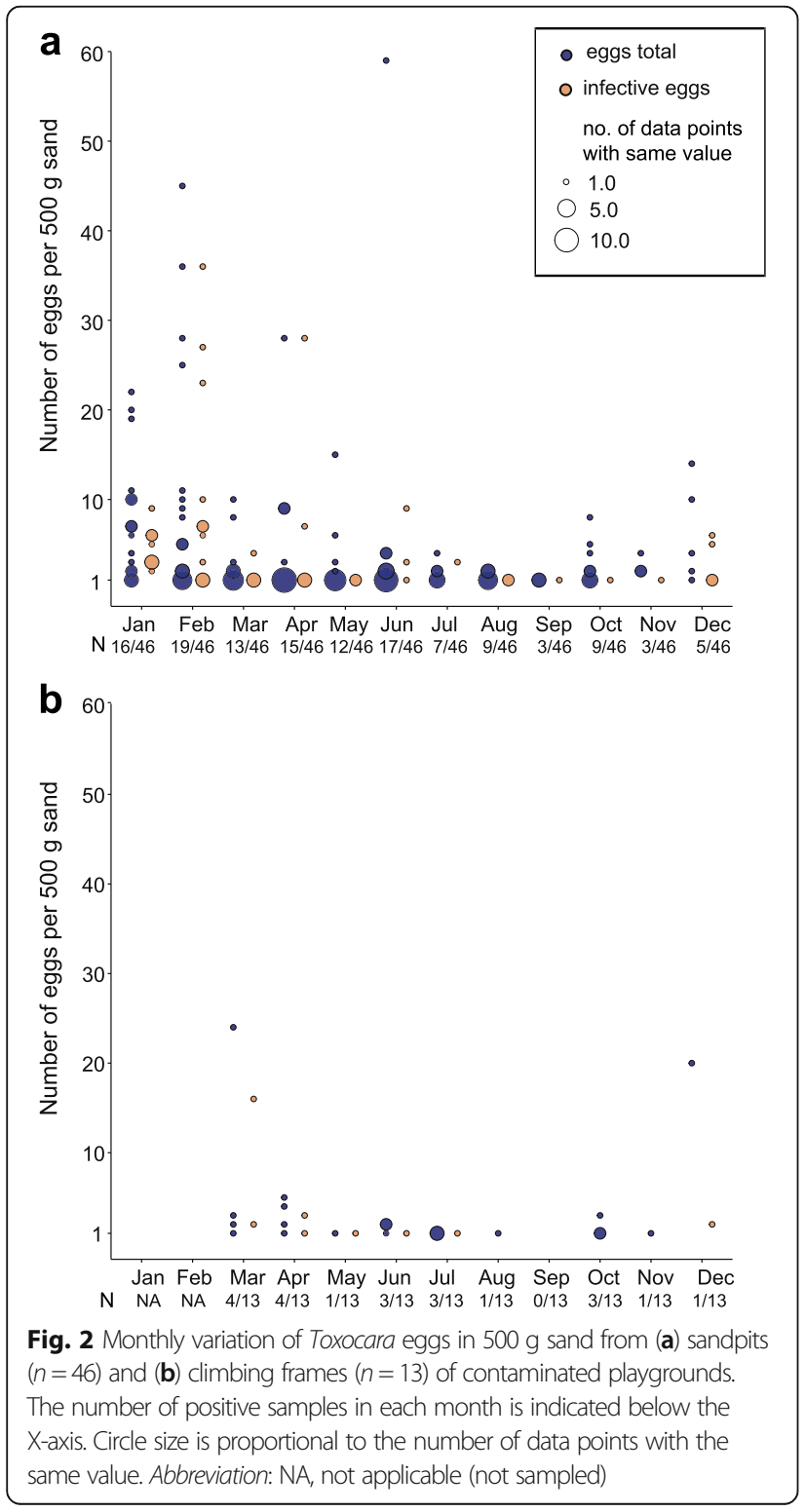

lowest contamination rate (Table 1; GLMM, likelihood ratio test: $\left.X^{2}=44.4, d f=11, P<0.001\right)$. Sandpit contamination with infective eggs was observed significantly more often in January and February as compared to September (Table 1; GLMM, likelihood ratio test: $\chi^{2}=$ 29.9, $d f=11, P=0.002$ ). The likelihood of contamination did not differ significantly between sandpits and climbing frames (Additional file 1: Table S1).

Regarding egg numbers, sandpit samples contained significantly more Toxocara eggs in October and from December to June as compared to September (Table 2, GLMM, likelihood ratio test: $\chi^{2}=65.89, d f=11, P<0.001$ ). The number of infective eggs per $500 \mathrm{~g}$ of sand was significantly higher in January, February and April (Table 2, GLMM, likelihood ratio test: $\chi^{2}=858.15, d f=11, P<$ 0.001 ). Again, there was no statistically significant difference between egg numbers in sandpit compared to climbing frame samples (Additional file 2: Table S2).

\section{Discussion}

Zoonotic roundworms of the genus Toxocara pose a threat to public health due to the clinical manifestations they may cause in humans, such as visceral and ocular larva migrans syndrome or neurotoxocarosis. The high seroprevalences reported globally highlight the need for contemporary studies assessing transmission risks originating from different reservoirs. It has been suggested that environmental transmission is the main source of infection for humans [6]. In children, a positive correlation between frequency of playing at contaminated public places and Toxocara seropositivity has been demonstrated $[10,11]$. Here, public playgrounds were surveyed for Toxocara eggs in the city of Hanover, Germany.

Monthly Toxocara contamination rates of sandpits ranged from $6.5 \%$ in September to $41.3 \%$ in February. Such range is comparable to current contamination rates found in Belgium and Poland [22, 23]. By contrast, Horn et al. [12], who used a similar egg detection method, found $55.8 \%$ of Hanoverian playgrounds to be contaminated with Toxocara eggs in August 1985. The apparent decrease in contamination rates may be attributed to the reduction in Toxocara prevalence in dogs and cats. Between 1984 and 1991, 6.9\% of dogs and 9.5\% of cats in Germany excreted Toxocara eggs with their faeces [13]. Between 2003 and 2012, these numbers dropped to $2.8-6.1 \%$ in dogs and $3.9-4.7 \%$ in cats [14; unpublished own diagnostic data based on 2,731 dog and 903 cat samples], probably due to improved awareness for parasites and anthelmintic management by veterinarians and pet owners. Similarly, only one out of 31 faecal samples found on playgrounds in the present study was positive for parasite eggs, including T. canis. Furthermore, only low average numbers of Toxocara eggs were detected in positive sand samples (4.9 total eggs/500 g of sand, 1.4 
Table 1 Results of GLMMs with binomial error structure testing monthly differences in contamination rates with total and embryonated infective Toxocara eggs in playground sandpits

\begin{tabular}{|c|c|c|c|c|c|}
\hline & Term & Estimate & Std. Error & $z$-value & $P$-value \\
\hline \multirow[t]{12}{*}{ Total contamination with Toxocara eggs } & Intercept & -2.70 & 0.60 & -4.49 & $<0.001^{* * *}$ \\
\hline & January & 2.09 & 0.68 & 3.09 & $0.002^{* *}$ \\
\hline & February & 2.34 & 0.67 & 3.49 & $<0.001^{* * *}$ \\
\hline & March & 1.75 & 0.68 & 2.56 & $0.01^{*}$ \\
\hline & April & 1.96 & 0.68 & 2.89 & $0.004^{* *}$ \\
\hline & May & 1.64 & 0.69 & 2.38 & $0.017^{*}$ \\
\hline & June & 2.16 & 0.67 & 3.20 & $0.001^{* *}$ \\
\hline & July & 0.95 & 0.73 & 1.31 & 0.190 \\
\hline & August & 1.26 & 0.71 & 1.79 & 0.074 \\
\hline & October & 1.26 & 0.71 & 1.79 & 0.074 \\
\hline & November & 0.00 & 0.85 & 0.00 & 0.999 \\
\hline & December & 0.56 & 0.76 & 0.74 & 0.462 \\
\hline \multirow{12}{*}{$\begin{array}{l}\text { Contamination with embryonated infective } \\
\text { Toxocara eggs }\end{array}$} & Intercept & -3.81 & 1.01 & -3.77 & $<0.001^{* * *}$ \\
\hline & January & 2.28 & 1.08 & 2.10 & $0.036^{*}$ \\
\hline & February & 2.68 & 1.07 & 2.51 & $0.012^{*}$ \\
\hline & March & 1.46 & 1.14 & 1.28 & 0.201 \\
\hline & April & 1.70 & 1.12 & 1.53 & 0.127 \\
\hline & May & 0.72 & 1.24 & 0.58 & 0.565 \\
\hline & June & 1.14 & 1.17 & 0.97 & 0.330 \\
\hline & July & 0.00 & 1.43 & 0.00 & 1.000 \\
\hline & August & 0.72 & 1.24 & 0.58 & 0.565 \\
\hline & October & 0.00 & 1.43 & 0.00 & 1.000 \\
\hline & November & 0.00 & 1.43 & 0.00 & 1.000 \\
\hline & December & 1.46 & 1.14 & 1.28 & 0.201 \\
\hline
\end{tabular}

${ }^{*} P \leq 0.05,{ }^{* *} P \leq 0.01,{ }^{* * *} P \leq 0.001$

September, the month with the lowest contamination rate, was chosen as reference. Asterisks indicate statistically significant differences

infective eggs/500 g of sand). In comparison, a number of 2.1 viable eggs per five grams of soil is considered as a high risk for human infection [24]. Thus, the infection risk for children playing on Hanoverian playgrounds is estimated to be moderate to low. However, because low infection doses may not stimulate the immune system adequately, they are considered to be the main cause of ocular toxocarosis [25]. Therefore, the risk for a single individual of acquiring Toxocara infections from sandpits should not be underestimated, as individual sand samples contained up to 36 infective eggs per $500 \mathrm{~g}$, probably due to recent contamination with faeces.

Over the course of the year, significant seasonal variation in Toxocara contamination rates as well as in egg numbers was found, indicating that infection risk may vary depending on the season. Percentage contamination rates were elevated from January to June, with January and February showing the highest contamination rate with infective eggs. Similarly, the number of Toxocara eggs per sandpit sample was elevated from December to
June, and highest numbers of infective Toxocara eggs were again found in January and February. Higher percentages of Toxocara contamination of playgrounds and public parks in winter and spring than in summer and autumn were also reported in other studies from Europe [23, 26], demonstrating a general pattern underlying this observation. Survival and development of Toxocara eggs depend on temperature, humidity and sunshine exposure [27, 28]. Development starts around $4{ }^{\circ} \mathrm{C}$ and accelerates with ascending temperatures, but as of $37{ }^{\circ} \mathrm{C}$, eggs are damaged. Development also increases with humidity, whereas during arid conditions, Toxocara eggs arrest development or die. The cool and wet winter weather in central Europe may facilitate egg survival over prolonged periods, resulting in accumulation of contamination during the first half of the year, whereas sunshine exposure and desiccation of sand during summer and autumn are a relevant cause for declining contamination during these seasons. Furthermore, dog owners may have stronger inhibitions to let their dogs 
Table 2 Results of GLMMs with negative binomial error structure testing the effect of month on the number of total and embryonated infective Toxocara eggs per sandpit sample

\begin{tabular}{|c|c|c|c|c|c|}
\hline & Term & Estimate & Std. Error & $z$-value & $P$-value \\
\hline \multirow[t]{12}{*}{ Total number of Toxocara eggs } & Intercept & -2.83 & 0.71 & -3.99 & $<0.001^{* * *}$ \\
\hline & January & 3.83 & 0.81 & 4.73 & $<0.001^{* * *}$ \\
\hline & February & 4.23 & 0.80 & 5.26 & $<0.001^{* * *}$ \\
\hline & March & 2.47 & 0.82 & 3.01 & $0.003^{* *}$ \\
\hline & April & 2.89 & 0.82 & 3.53 & $<0.001^{* * *}$ \\
\hline & May & 2.44 & 0.83 & 2.96 & $0.003^{* *}$ \\
\hline & June & 3.04 & 0.82 & 3.70 & $<0.001^{* * *}$ \\
\hline & July & 1.30 & 0.86 & 1.52 & 0.128 \\
\hline & August & 1.49 & 0.85 & 1.74 & 0.082 \\
\hline & October & 2.04 & 0.83 & 2.46 & $0.014^{*}$ \\
\hline & November & 0.92 & 0.88 & 1.05 & 0.294 \\
\hline & December & 2.17 & 0.84 & 2.60 & $0.009^{* *}$ \\
\hline \multirow{12}{*}{$\begin{array}{l}\text { Number of embryonated infective } \\
\text { Toxocara eggs }\end{array}$} & Intercept & -4.06 & 1.18 & -3.43 & $<0.001^{* * *}$ \\
\hline & January & 3.74 & 1.32 & 2.83 & $0.005^{* *}$ \\
\hline & February & 4.89 & 1.32 & 3.71 & $<0.001^{* * *}$ \\
\hline & March & 1.90 & 1.37 & 1.39 & 0.164 \\
\hline & April & 3.27 & 1.36 & 2.41 & $0.016^{*}$ \\
\hline & May & 0.57 & 1.49 & 0.38 & 0.704 \\
\hline & June & 2.04 & 1.38 & 1.47 & 0.141 \\
\hline & July & 0.60 & 1.49 & 0.40 & 0.687 \\
\hline & August & 0.71 & 1.48 & 0.48 & 0.631 \\
\hline & October & -0.30 & 1.68 & -0.18 & 0.858 \\
\hline & November & -0.07 & 1.64 & -0.04 & 0.965 \\
\hline & December & 2.36 & 1.35 & 1.75 & 0.081 \\
\hline
\end{tabular}

${ }^{*} P \leq 0.05,{ }^{* *} P \leq 0.01,{ }^{* * *} P \leq 0.001$

September, the month with the lowest contamination rate, was chosen as reference. Asterisks indicate statistically significant differences

run on playgrounds during summer months, when these are frequently visited by children. Additionally, seasonal patterns of Toxocara prevalence and egg shedding in the definitive host may cause seasonal variation in contamination rates. In dogs, patent $T$. canis infections peak during wintertime, possibly related to the reproductive biology of the host [29]. In the present study, eggs of T. canis and T. cati could not be microscopically differentiated, and a PCR-based approach was unsuccessful, probably due to UV-degradation of DNA (unpublished results). In a numerical model which estimated the contribution of different host species to environmental Toxocara contamination in Bristol, UK, dogs were predicted to shed the majority of Toxocara eggs into the environment, at least when removal of faeces by dog owners was neglected [30]. However, this study did not take differences between host species with regard to defecation habits into account. Therefore, it may be suggested that a significant proportion were $T$. cati eggs as shown on Japanese sandpits [31] and in urban areas of Poland [26], as cats prefer sandy substrates for defecation rather than dogs. Building upon the model by Morgan et al. [30], Nijsse et al. [32] suggested cats to be the main source of Toxocara egg contamination in urban areas in the Netherlands. Furthermore, contamination by wildlife needs to be considered. Urban fox populations, which display high $T$. canis prevalences, have been on the rise all over Europe and may represent a non-negligible reservoir [33]. For example, $59 \%$ of foxes were found to be infected with Toxocara canis in Denmark [34]. In the numerical model mentioned above, foxes were predicted to constitute the main source of Toxocara eggs in Bristol, UK, at high levels of faeces removal by dog owners [30]. Similar to dogs, foxes display a peak in Toxocara prevalence during the reproductive period in spring [33]. Remarkably, no hookworm eggs or any other zoonotic geohelminths apart from Toxocara were found on the playgrounds. However, the used method for egg recovery from sand [19] is only evaluated for Toxocara eggs, and hookworm larvae may have hatched from eggs during desiccation of sand samples. 
To reduce Toxocara contamination of sandpits, fencing of playgrounds has proven effective in some studies [35], whereas other measures, like covering sandpits overnight, may not be feasible on public playgrounds. Considering that Toxocara eggs may accumulate over time, the interval in which sand is replaced might also have an influence on contamination. In the city of Hanover, sand in sandpits is regularly replaced every three years, whereas the replacement interval for sand underneath climbing frames is five years. Therefore, a higher contamination rate of climbing frames than sandpits was expected. However, contamination rates, as well as egg numbers of climbing frame samples, did not differ from sandpit samples, indicating that in this case decontamination was mainly due to dehydration and UV-exposure. Shorter sand replacement intervals, e.g. at the end of winter when playground contamination rates are high, would further decrease Toxocara contamination. However, this would be logistically challenging and costly to implement. Alternatively, complete removal of sandpits from public parks might be considered.

\section{Conclusions}

Even though Toxocara contamination of playgrounds in the city of Hanover has decreased since 1985, infective Toxocara eggs are still present on up to almost every fourth playground. Contamination rates were elevated from January to June, and the highest proportion of infective embryonated eggs was observed in January and February. On average, the number of eggs per $500 \mathrm{~g}$ of sand was low, indicating a moderate to low infection risk for children. However, highly contaminated spots may occur infrequently and independent of season, constituting a potential source of infection which should not be underestimated. If sandpits are maintained on playgrounds, public health authorities should implement shorter sand replacement intervals and promote the education of the public regarding the risk of zoonotic Toxocara infections.

\section{Additional files}

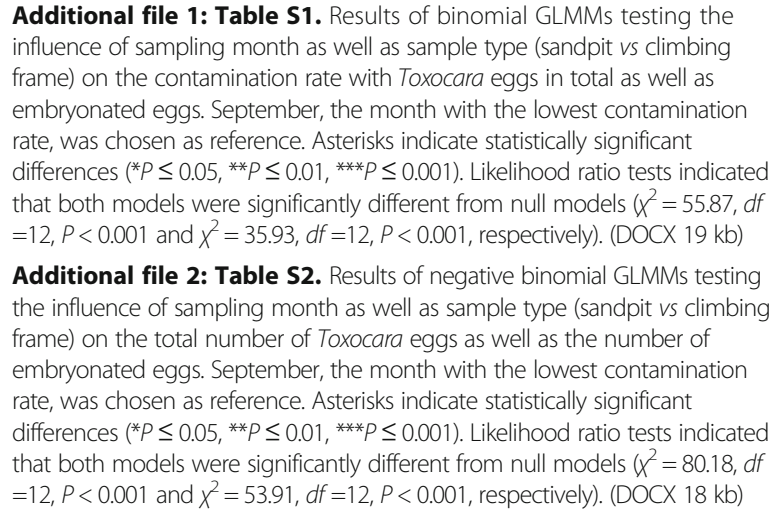

Additional file 1: Table S1. Results of binomial GLMMs testing the influence of sampling month as well as sample type (sandpit vs climbing frame) on the contamination rate with Toxocara eggs in total as well as embryonated eggs. September, the month with the lowest contamination rate, was chosen as reference. Asterisks indicate statistically significant differences $\left({ }^{*} P \leq 0.05,{ }^{* *} P \leq 0.01,{ }^{* * *} P \leq 0.001\right)$. Likelihood ratio tests indicated that both models were significantly different from null models $\left(x^{2}=55.87, d f\right.$ $=12, P<0.001$ and $X^{2}=35.93, d f=12, P<0.001$, respectively). (DOCX $19 \mathrm{~kb}$ )

Additional file 2: Table S2. Results of negative binomial GLMMs testing the influence of sampling month as well as sample type (sandpit vs climbing frame) on the total number of Toxocara eggs as well as the number of embryonated eggs. September, the month with the lowest contamination rate, was chosen as reference. Asterisks indicate statistically significant differences $\left({ }^{*} P \leq 0.05,{ }^{* *} P \leq 0.01,{ }^{* *} P \leq 0.001\right)$. Likelihood ratio tests indicated that both models were significantly different from null models $\left(x^{2}=80.18, d f\right.$ $=12, P<0.001$ and $X^{2}=53.91, d f=12, P<0.001$, respectively). (DOCX $18 \mathrm{~kb}$ )

\section{Abbreviations}

GLMMs: Generalised linear mixed models; OLM: Ocular larva migrans syndrome; VLM: Visceral larva migrans syndrome

\section{Acknowledgements}

Not applicable.

\section{Funding}

Not applicable.

\section{Availability of data and materials}

The datasets supporting the conclusions of this article are included within the article and its additional files.

\section{Authors' contributions}

AK carried out sand sampling and laboratory work. AS performed the statistical analyses. CS designed and coordinated the study. All authors read and approved the final manuscript.

\section{Competing interests}

The authors declare that they have no competing interests.

\section{Consent for publication}

Not applicable.

Ethics approval and consent to participate Not applicable.

\section{Publisher's Note}

Springer Nature remains neutral with regard to jurisdictional claims in published maps and institutional affiliations.

Received: 8 March 2017 Accepted: 12 May 2017

Published online: 19 May 2017

\section{References}

1. Centers for Disease Control and Prevention. http://www.cdc.gov/parasites/ toxocariasis/. Accessed 1 May 2017

2. Strube C, Heuer L, Janecek E. Toxocara spp. infections in paratenic hosts. Vet Parasitol. 2013;193:375-89.

3. Walsh MG, Haseeb MA. Reduced cognitive function in children with toxocariasis in a nationally representative sample of the United States. Int J Parasitol. 2012;42:1159-63.

4. Hamilton CM, Stafford P, Pinelli E, Holland CV. A murine model for cerebral toxocariasis: characterization of host susceptibility and behaviour. Parasitology. 2006;132:791-801.

5. Overgaauw PA. Aspects of Toxocara epidemiology: toxocarosis in dogs and cats. Crit Rev Microbiol. 1997;23:233-51.

6. Holland CV. Knowledge gaps in the epidemiology of Toxocara: the enigma remains. Parasitology. 2015:1-14. doi:10.1017/S0031182015001407.

7. Stensvold CR, Skov J, Moller LN, Jensen PM, Kapel CM, Petersen E, Nielsen $\mathrm{HV}$. Seroprevalence of human toxocariasis in Denmark. Clin Vaccine Immunol. 2009;16:1372-3.

8. Deutz A, Fuchs K, Auer H, Kerbl U, Aspock H, Kofer J. Toxocara-infestations in Austria: a study on the risk of infection of farmers, slaughterhouse staff, hunters and veterinarians. Parasitol Res. 2005;97:390-4.

9. Magnaval JF, Michault A, Calon N, Charlet JP. Epidemiology of human toxocariasis in La Reunion. Trans R Soc Trop Med Hyg. 1994;88:531-3.

10. Paludo ML, Falavigna DL, Elefant GR, Gomes ML, Baggio ML, Amadei LB, Falavigna-Guilherme AL. Frequency of Toxocara infection in children attended by the health public service of Maringa, south Brazil. Rev Inst Med Trop Sao Paulo. 2007;49:343-8.

11. Manini MP, Marchioro AA, Colli CM, Nishi L, Falavigna-Guilherme AL. Association between contamination of public squares and seropositivity for Toxocara spp. in children. Vet Parasitol. 2012;188:48-52.

12. Horn K, Schnieder T, Stoye M. Contamination of public children's playgrounds in Hannover with helminth eggs. Dtsch Tierarztl Wochenschr. 1990;97(122):124-5.

13. Epe C, Ising-Volmer S, Stoye M. Parasitological fecal studies of equids, dogs, cats and hedgehogs during the years 1984-1991. Dtsch Tierarztl Wochenschr. 1993;100:426-8. 
14. Barutzki D, Schaper R. Results of parasitological examinations of faecal samples from cats and dogs in Germany between 2003 and 2010. Parasitol Res. 2011;109:45-60.

15. Official website of the City of Hanover. http://www.hannover.de/Leben-inder-Region-Hannover/Politik/Wahlen-Statistik/Statistikstellen-von-Stadt-undRegion/Statistikstelle-der-Landeshauptstadt-Hannover/Hannover-in-Zahlen. Accessed 26 Apr 2017

16. Mizgajska H. Eggs of Toxocara spp. in the environment and their public health implications. J Helminthol. 2001;75:147-51.

17. Gordon HM, Whitlock HV. A new technique for counting nematode eggs in sheep faeces. J Counc Sci Ind Res. 1939;12:50-2.

18. European Committee for Standardization. European Standard EN 13183-1: 2002/AC: Moisture content of a piece of sawn timber - Part 1: Determination by oven dry method. Brussels; 2002.

19. Kleine A, Janecek E, Waindok P, Strube C. Flotation and adherence characteristics of Toxocara canis and $T$. cati and a reliable method for recovering Toxocara eggs from soil. Vet Parasitol. 2016;227:35-41.

20. R Core Team. R Foundation for Statistical Computing, Vienna: Austria; 2016 $R$ : A language and environment for statistical computing. https://www.Rproject.org/.

21. Bates $D$, Mächler $M$, Bolker B, Walker S. Fitting linear mixed-effects models using Ime4. J Stat Softw. 2014:67:1-48.

22. Vanhee M, Dalemans AC, Viaene J, Depuydt L, Claerebout E. Toxocara in sandpits of public playgrounds and kindergartens in Flanders (Belgium). Vet Parasitol. 2015;1-2:51-4.

23. Kroten A, Toczylowski K, Kiziewicz B, Oldak E, Sulik A. Environmental contamination with Toxocara eggs and seroprevalence of toxocariasis in children of northeastern Poland. Parasitol Res. 2016;115:205-9.

24. Woodruff AW, Watson J, Shikara I, Al Azzi NS, Al Hadithi TS, Al Adhami SB, Woodruff PW. Toxocara ova in soil in the Mosul District, Iraq, and their relevance to public health measures in the Middle East. Ann Trop Med Parasitol. 1981;75:555-7.

25. Glickman LT, Schantz PM. Epidemiology and pathogenesis of zoonotic toxocariasis. Epidemiol Rev. 1981;3:230-50

26. Mizgajska-Wiktor H, Jarosz W, Fogt-Wyrwas R, Drzewiecka A. Distribution and dynamics of soil contamination with Toxocara canis and Toxocara cati eggs in Poland and prevention measures proposed after 20 years of study. Vet Parasitol. 2017;234:1-9.

27. Gamboa Ml. Effects of temperature and humidity on the development of eggs of Toxocara canis under laboratory conditions. J Helminthol. 2005;79:327-31.

28. Okoshi S, Usui M. Experimental studies on Toxascaris leonina. IV. Development of eggs of three ascarids, T. leonina, Toxocara canis and Toxocara cati, in dogs and cats. Nihon Juigaku Zasshi. 1968;30:29-38.

29. Nijsse R, Mughini-Gras L, Wagenaar JA, Ploeger HW. Recurrent patent infections with Toxocara canis in household dogs older than six months: a prospective study. Parasit Vectors. 2016;9:531.

30. Morgan ER, Azam D, Pegler K. Quantifying sources of environmental contamination with Toxocara spp. eggs. Vet Parasitol. 2013;193:390-7.

31. Shimizu T. Prevalence of Toxocara eggs in sandpits in Tokushima city and its outskirts. J Vet Med Sci. 1993:55:807-11.

32. Nijsse R, Mughini-Gras L, Wagenaar JA, Franssen F, Ploeger HW. Environmental contamination with Toxocara eggs: a quantitative approach to estimate the relative contributions of dogs, cats and foxes, and to assess the efficacy of advised interventions in dogs. Parasit Vectors. 2015:8:397.

33. Reperant LA, Hegglin D, Fischer C, Kohler L, Weber J-M, Deplazes P. Influence of urbanization on the epidemiology of intestinal helminths of the red fox (Vulpes vulpes) in Geneva. Switzerland Parasitol Res. 2007;101:605-11.

34. Saeed I, Maddox-Hyttel C, Monrad J, Kapel CMO. Helminths of red foxes (Vulpes vulpes) in Denmark. Vet Parasitol. 2006;139:168-79.

35. Blaszkowska J, Goralska K, Wojcik A, Kurnatowski P, Szwabe K. Presence of Toxocara spp. eggs in children's recreation areas with varying degrees of access for animals. Ann Agric Environ Med. 2015;22:23-7.

\section{Submit your next manuscript to BioMed Central and we will help you at every step:}

- We accept pre-submission inquiries

- Our selector tool helps you to find the most relevant journal

- We provide round the clock customer support

- Convenient online submission

- Thorough peer review

- Inclusion in PubMed and all major indexing services

- Maximum visibility for your research

Submit your manuscript at www.biomedcentral.com/submit
) Biomed Central 